\title{
The Role of Metonymy in the Formation of Euphemism in Chinese and English
}

\author{
Yeli Shi \\ Foreign Language College, Zhejiang Ocean University, Zhoushan City, Zhejiang Province, 316000, China \\ Email: willa504@163.com \\ Jinfang Sheng \\ Foreign Language College, Zhejiang Ocean University, Zhoushan City, Zhejiang Province, 316000, China
}

\begin{abstract}
Euphemism is a widespread language phenomenon and indispensable lubricant in language communication. It is an expression, which can show politeness, ease the tone and coordinate the personal relationships. It can be found out that many English and Chinese euphemisms are generated in the framework of conceptual metonymy in daily life. The study of euphemisms from the perspective of cognitive metonymy enjoys its significance in language learning, cross-cultural communication and translation of euphemisms.
\end{abstract}

Index Terms - euphemism, metonymy, generating mechanism

\section{INTRODUCTION}

As a common language phenomenon, euphemism has been studied from different perspectives. With the development of cognitive linguistics, metonymy was introduced to the formation of euphemism. Some cognitive theories like conceptual metonymy, advocated by Lakoff, paved the way for further study on metonymy and the formation of euphemism. The current studies on euphemism are mainly built on traditional semiotic semantics and pragmatics. Due attention still has not been given to the euphemism and its generating mechanism in the scope of metonymy. Yet, using euphemism properly is still a difficulty for English learners. Thus, the author of this paper intends to further explore the role metonymy plays in the formation of euphemism both in English and Chinese.

\section{THE RELATION BETWEEN EUPHEMISM AND METONYMY}

The word "euphemism" was first put forward by George Blunt in 1580s. Derived from Greek, euphemisms are words of "good omen" or "good speech" literally. Up to date, there is no universal agreement about the definition of euphemism. Generally, euphemism is often defined as "substituting an inoffensive or pleasant term for a more explicit, offensive one, thereby veneering the truth by using kind words" (Neaman \& Silver, 1983, p.4).

With the naissance and development of cognitive linguistics, conceptual metonymy has been emphasized by linguists. As stated by Lakoff (1987), metonymy is one of the basic characteristics of cognition. It is extremely common for people to take one well-understood or easy-to-perceive aspect of something and use it to stand either for the thing as a whole or for some other aspect or part of it. In addition, metonymy is a situation in which some subcategory or member or sub-model is used (often for some limited and immediate purpose) to understand the category as a whole, that is, there are cases where a part (a subcategory or member or sub-model) represents the whole category in reasoning, recognition, etc. Metonymy is not random or arbitrary occurrence, it is systematic. For these cognitive features and functions of metonymy, there is no difficulty associating conceptual metonymy with the formation of euphemism.

With the understanding of definition, functions and characteristics of euphemism, we can find that many euphemisms are generated in the framework of conceptual metonymy in our daily life. According to cognitive linguistics, the generation manifests itself in two ways: within the same cognitive domain, whole and part metonymic relationship and part and part metonymic relationship. What's more, there also exists other ways to generate euphemism, such as lexical device, pragmatic device, and grammatical device.

\section{Metonymic APPROACH to the Generating Mechanism of Euphemism}

The vagueness and indirectness of euphemism rely on conceptual metonymy. The explanation of the relation between euphemism and metonymy gives us a clear understanding that metonymic mechanism works on the basis of contiguity or relevance between things. There are mainly two types of metonymic approaches to the generating mechanism of euphemism, that is, whole and part metonymic relationship and part and part metonymic relationship.

\section{A. Whole and Part Metonymic Relationship}

From the angle of cognitive linguistics, the whole and part metonymic relationship is applied to things related. Here are two variants: the whole stands for the part and the part replaces the whole. 
The whole stands for the part: generally, people tend to use euphemism to avoid embarrassment. When referring to the organ, they prefer to broaden the conception of organs, for example, "the chest", "the bosom" are often used for "breast", and they use "rear end", "back parts", "behind" and "posterior" to replace "buttocks". Concerning sex, people may feel uncomfortable, in this sense, "the fact of life" usually stands for "the knowledge of sex" and "having sexual relationship with someone” can be replaced by “going to bed with someone”. In Chinese, “他在外面有女人”(he has a woman outside), which really means "he has a mistress". Here the conception of "woman" is broadened, replacing the sensitive word "mistress".

In the case of metonymy the part for the whole, there are many parts that can stand for the whole. "Which part is picked out determines which aspect of the whole we are focusing on" (Lakoff \&Johnson, 1980, p.36). On public occasions, it is polite to say "cloakroom" or "powder room" to refer to the lavatory, which could make people feel eased. People tend to say "he is lazy bones" instead of "he is a lazy person". "we don't need any green hand", the "green hand" refers to a person who lacks experience. For another example, "we need some good heads", "the good heads" here refers to intelligent people. In analyzing the cases above, "the point is not just to use a part to stand for a whole, but rather to pick out a particular characteristic of the person” (Lakoff \&Johnson, 1980, p.36).

\section{B. Part and Part Metonymic Relationship}

Metonymies are not random or arbitrary occurrence to be treated as isolated instances. It serves as a bridge to link two things. Metonymic concepts are also systematic, as can be seen in the replacement of the place for the event, the material constituting an object for the object, producer for the product, object used for user, institution for person responsible, and the place for the institution.

The metonymic relation by using a place to stand for an event is pervasive, particularly in the case of death. Death is simply a natural process that will come to anyone. Euphemisms for death both in English and Chinese are universal. In western countries, "the place of God", "heaven" generally refers to death. In the case that "he is knocking on heaven's door", "he is called to home", or "he is asleep in the arms of the God", are euphemisms in a polite mood, showing respect for the dead. While in China, deeply influenced by the Taoism or Buddhism, death is usually associated with “the west” or “western paradise”. Death simply means that the flesh and blood turns into spirit, which can be called “归 西”(go to the west), “极乐世界”(free from all worries).

Close to our daily life, the relationship of the material constituting an object for the object is pervasive. For instance, "poppy" stands for "opium", which is made from poppy; and "bamboo" for "opium pipe", which is made of bamboo. In Chinese, “一掊土”(a pile of soil) is for “坟墓”(tomb), “寿木”is for “棺材”(coffin), which is visual for understanding.

Similarly, the relationship of replacement of producer for the product can be supported with the example of "the Ford" for the car produced in Ford Company.

The replacement of object used for user, we find that English and Chinese euphemisms are somewhat similar in expression. In English, instead of saying "he is fond of wine", people may use "he is fond of bottles". Similarly in Chinese, we employ “enjoy bottles"(贪杯) to mean "like drinking” euphemistically. For bottle and wine has the contiguity, the usage of bottle in place of wine has the purpose of diverting people's attention.

With regard to the place for the institution, "White House", "Wall Street", "Hollywood" and the like are typical examples. In the replacement, the place cannot equal the institution, for they belong to different conceptual domains. However, human beings' subjective initiative does a lot in expressing euphemistically.

Apart from those relationships mentioned above, there also exists the replacement of the characteristics for the thing itself, which cannot be ignored. Fear of diseases and disability has led us to use a number of euphemisms to replace them. For instance, "inconvenient" is used to substitute "lame". In English, "the disabled", "the handicapped", "the inconvenient", "the invalid", "auditory impaired", "hard of hearing" or "talk with one's fingers" are widely used. In Chinese, we use “physically disabled”(生理上有缺陷) instead of “crippled”(残废), “low children”(智障儿童) instead of “stupid children”(弱智儿童).

\section{Metonymic DeVices of Generating EUPHEMism}

Apart from the metonymic approach to the generating mechanism of euphemism, there also exist microscopic aspects: the generating devices of euphemism, including lexical device, grammatical device and pragmatic device.

\section{A. Lexical Device}

In the level of lexical device, euphemisms can be mainly divided into three types: borrowed words, abbreviation and vague words.

\section{a. Borrowed Words}

One of the generating devices of euphemism is borrowed words that come from the other languages such as Greek, Latin, French, Italian, etc. There are a large number of foreign words to replace the tabooed or sensitive words in one's native language to form euphemism both in English and Chinese. Those foreign words and the native ones are equivalent in meaning. Because of people's relative unfamiliarity with a certain foreign language, foreign words can 
bring about a certain sense of mildness and implicitness, so as to avoid embarrassment. Psychologically, borrowed words can produce certain distance between symbols and tabooed referents (Lu, 2006).

English vocabulary has the quality of receptiveness and its speed of receiving foreign components is fast, the same with English euphemism. In English, borrowed euphemisms come mainly from French and Latin. Euphemism like "euceinte" is from French replacing pregnancy, "micturition" or "urination" from Latin to stand for piss. We have examples such as "euthanasia", which borrowed from Greek, and now become popular in China. In addition, borrowed euphemisms in Chinese are generally from English. For instance, "the water closet" for WC, and nowadays, young people tend to say "I love you" instead of saying in mandarin “我爱你”.

The borrowed words from foreign languages reflect the psychology of people in pursuing new things, and importantly achieve the euphemistic effect.

\section{b. Abbreviation}

Borrowing words from other countries is the characteristic of euphemism. Abbreviation is another method. Abbreviation is a short form of a word, which can be further divided into three types: clipping, acronym and initialism, and blend.

Clipping, or cutting, is a part of a longer word. Clipped words seem to be casual but very useful. "Gents" for "gentlemen's room", "lav" for "lavatory", both are the toilet in an implicit way, which is the principle of euphemism to be pleasant.

Acronym and initialism are abbreviations that are formed using the initial components in a phrase or a name. Fears of some diseases, people tend to say the diseases in this way, there is no difficulty for us to set examples. "TB" is used to stand for tuberculosis; cancer is replaced with " $\mathrm{C}$ ". There are also euphemisms for occupation, especially in English. In western countries, one's occupation is an indicator of his economic or social status, particular for those who have low-paid and humble occupation. They are sensitive to their occupational status in society. For the sake of their faces, initialism and acronym are widely used. For instance, garbage man is often called "G-man", which can avoid offending them.

A blend is a combination of parts of two words to form a third word which contains some of the meaning of each part. Euphemisms both in English and Chinese contain some sensitive words, which could cause embarrassment. By using blend words, it does a lot in personal communication. There is no wonder that blend words are universal. For example, "chexting" is a blend of "cheating" and "texting". "sexcapade" is a blend of "sex" and "escapade".

\section{c. Vague Words}

Vague words and expressions can blur the undesirable associations of tabooed words and produce euphemistic effect. "Hyponymy, as one of the ways of using vague words, refers to a paradigmatic relation between one or more specific or subordinate lexical terms and a general or super-ordinate lexical term" (Lu \&Kong, 2006, p.19). For example, "animal" stands for pig and "lily" is for flower. In these cases, hyponyms are the direct expressions and their super-ordinates are their euphemisms. It has achieved the effect of vagueness for weakening the sense of unpleasantness. In English, there are many euphemisms of this kind, such as the "economic things" for economic crisis or economic depression, "in difficulty" for poor, "a growth" for cancer, "full-bodied", "king-sized" for fat etc. It is true for Chinese and English. Chinese vague expressions such as “have another one”(有外遇), “the third party”(第三者) are used to replace “have illegal relationship" euphemistically. In English, similar meanings are expressed vaguely like "have affair with someone", "to work late at the office" etc.

The use of pronoun is another way of using vague words. For instance, the words "it" and "that" are of a high degree of vagueness. They are featured with generality and ambiguity. Similarly in Chinese, the pronoun “it" or “that" (那个) can refer to almost all the tabooed behaviors.

\section{B. Grammatical Device}

Euphemisms are not restricted to the lexicon. Besides, there are grammatical ways of toning something without changing the content of the message. Such grammatical device includes tense, negation and ellipsis.

\section{a. Tense}

Tense and modal words are two pervasive methods for the creation of English euphemisms, which cannot be realized in Chinese. Past tense, past progressive tense and modal words like "should", "would" are often used in communication to make sentences sound more polite. Besides, the continuous tense, passive voice, interrogative sentences and subjunctive mood all play vital roles in euphemism of English and Chinese.

The past tense indicates that the action happened in the past and distant from the moment of speaking. And distance becomes the key of past tense, which contains the distance in time, reality and psychology. In this way, the hearer does not feel embarrassed because of the distance. So the euphemistical effect is attached. For example, "I wondered if you could give me a hand with the painting" actually implies the meaning of "help me with my painting". Both sentences convey the same meaning, yet the former includes the past tense seems milder and more euphemistic than the simple tense.

The continuous tense attaches importance to the temporariness. In other words, the speaker's intention is only a temporary and inadequately-considered thought. Thus, if the hearer refuses, it does not threaten faces of both sides (Li, 2004). For example, "I'm waiting to see you" is a euphemistic way of expressing "see you". 
The passive voice used in sentence becomes much milder and more euphemistic. In passive voice, subject of a sentence is the receiver of the action and stresses the objectiveness, thus avoiding the agent of action.

The interrogative sentences both in English and Chinese are much milder and more euphemistic than those in imperative sentences. Therefore interrogative sentences play a vital role in the use of euphemisms. When we say in imperative, it gives us the sense of toughness and order; in contrast, interrogative sentences are refraining from the strength. In comparison the sentence "Go and do you housework." with "Would you go and do you housework?" the latter one is more polite and euphemistic. In Chinese, “Are you not considerate of your parents”(难道你还不体谅父母) is the euphemistic way of expressing “You must be considerate of your parents”(你必须体谅你父母).

b. Negation

Negation is one of the ways of conveying the euphemistic meaning. In English, for euphemistic purpose, the word "not" is often used before words such as "think, believe, suppose, expect, imagine and appear" etc, to form transferred negation. For instance, "I don't think he is right" conveys the same meaning of "I think he is wrong". The tone of transferred negation sounds milder and can make expressions more implicit, thus lessening the offense to the listeners and strengthening the euphemistic effect.

In Chinese, negative prefixes can also work in this aspect. We often use “not tall”(不高) to stand for “short”(矮), “not beautiful”(不漂亮) for “ugly”(丑). Similarly, “be not well”(不舒服) to replace “be sick”(有病) or “get sick”(生病). In this way, euphemism effect is achieved and faces of the listeners saved. Apart from those negative prefixes, there are also some negatives such as “not too much”(不很), “not necessary”(不必) and “be unlikely to”(未必), often employed to make sentences implicit. As seen in the sentence "It is not necessary to buy the coat", which conveys the meaning of "don't buy the coat", this kind of negative expression softens the tone of the sentence and achieves the euphemistic effect.

c. Ellipsis

Ellipsis is the act of leaving out a word or words from a sentence deliberately, when the meaning can be understood without them. It is also a good way to form euphemisms in English and Chinese. In order to strengthen euphemistic effect, we can leave out the unpleasant words. Because of its familiarity in our daily life, it is without difficulty for us to set examples. "She is expecting" stands for "she is expecting a baby", here the word "baby" being omitted. And "have relations with someone" is in place of "have sexual relation with someone". Similarly in Chinese, we use "have"(有了) to refer to “pregnant”(有了身孕). Moreover, in Chinese, signs like "xxx" are often seen in literary works, which are regarded as the symbols of omission. Generally, the vague or unpleasant words are omitted to achieve euphemism.

\section{Pragmatic Device}

In the use of language, euphemistic effect is dependent on the situational context which, sometimes, plays an important part in expressing euphemism. As seen in the dialogue between the two persons: "What do you think of this dress?" "Oh, it's nice weather today", we know that the answer is not related to the question. What the answer really conveys is that the dress is not so good. The context is important to the construction of the euphemistic meaning (Lu \& Kong, 2006). When talking about the topics such as criminal in Chinese, we say "he is in"(他进去了). What we want to convey is that "he is in prison”(他进监狱了). Referring to extramarital affairs, love affairs, we often use the prefix “that”(那个) to stand for illegal sexual relationships.

In order to achieve the euphemistic effect, speakers may use interrogative sentences instead of imperative sentences. It is typically a pragmatic device. For instance, the sentence "Can you pass me the salt?" literally a question about the hearer's ability to pass the salt, pragmatically, a request is made indirectly so as to produce the euphemistic effect.

\section{CONCLUSION}

As a common language phenomenon, euphemism has a great significance in language learning and plays an increasingly important role in communication. The formation of English and Chinese euphemisms is vital in the framework of conceptual metonymy. From the perspective of linguistics, euphemism and metonymy are closely related. Metonymy plays a vital role in the formation of euphemism. With the use of conceptual metonymy, people tend to replace the tabooed or sensitive words with euphemisms generated by conceptual metonymy. With the help of conceptual metonymy, euphemistic effect is strengthened, and embarrassment is avoided.

\section{REFERENCES}

[1] Lakoff, J. (1987).Women, Fire, and Dangerous Things. Chicago: The University of Chicago Press.

[2] Lakoff, J. \& Johnson, M. (1980). Metaphors We Live By. Chicago: The University of Chicago Press.

[3] Neaman, J. S. \& Silver, C. G. (1983). Kind Words_-A Treasure of Euphemisms. New York: Facts on File. World Publishing Corp.

[4] Weizhong, Lu. \& Shujuan, Kong. (2006). The Role of Metonymy in the Formation of Euphemism. Foreign Languages Research, 100/6, 17-20.

[5] Guonan, Li. (2004). Metaphorical cognitive model of the past tense of English verbs. Foreign Language Teaching and Research, 36/1,37-41. 
Yeli Shi was born in Zhejiang, China in 1967. She received her M.A. degree in English Language and Literature from Zhejiang University, China in 2004.

She is currently an associate professor in the School of Foreign Languages, Zhejiang Ocean University, China. Her research interests include cognitive linguistics and teaching methodology.

Jinfang Sheng is a graduate majoring in English with bachelor's degree. 